\title{
SERUM NEOPTERIN AND PROCALCITONIN LEVELS IN RELATIONSHIP WITH PEDIATRIC BURN WOUND INFECTIONS
}

\author{
OzGur Pilanci $^{1}$, Sevgi Ergin ${ }^{2}$, Serhat SireKBasAn ${ }^{2}$, Idris Ersin ${ }^{1}$,

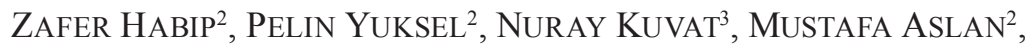 \\ OYKU DINC ${ }^{2}$, SUAT SARIBAS ${ }^{2}$, BEKIR KOCAZEYBEK ${ }^{2 *}$ \\ ${ }^{1}$ Department of Plastic, Reconstructive and Aesthetic Surgery, \\ Bagcilar Training and Research Hospital, Istanbul, Turkey \\ ${ }^{2}$ Department of Medical Microbiology, Cerrahpasa Medical Faculty, \\ Istanbul University, Istanbul, Turkey \\ ${ }^{3}$ Department of Medical Microbiology, Haseki Research and Training Hospital, \\ Istanbul, Turkey
}

(Received: 5 June 2015; accepted: 15 October 2015)

Infection and septic complications in burn patients can be monitored by procalcitonin (PCT) and neopterin plasma values. The aim of the study was to investigate serum neopterin and PCT levels with WBC (white blood cell) and CRP (C-reactive protein) levels in patient group (PG) and healthy control group (HCG) and to investigate the relationship of these markers with burn wound infections (BWI). As the PG, 23 patients between 0-12 ages and up to 30\% Total Body Surface Area (TBSA) burned and 15 HCG were included. PCT, neopterin, WBC, and CRP results on the first, the seventh, the fourteenth and the $21^{\text {st }}$ day have been compared. During the follow-up period, 11 patients with BWI and 12 patients without BWI were classified as infected and non-infected patients, respectively. PCT and neopterin levels were detected higher in patients with BWI but no significant difference were present. Also, PCT and neopterin levels within the first 24 hours following the burn were detected higher in PG than HCG. CRP and WBC levels were detected high due to burn trauma. PCT and neopterin levels were increased in patients with BWI. PCT levels were increased during the pre-infectious period, while neopterin levels increased during the post-infectious period.

Keywords: burns, burn wound infection, procalcitonin, neopterin

\footnotetext{
*Corresponding author; E-mail: bzeybek@istanbul.edu.tr
} 


\section{Introduction}

The prominent causes of mortality in burn patients are burn shock, respiratory failure and septic complications that develop in the subsequent days [1]. Immune deficiency and late-onset sepsis continue to be an important problem and immunological anomalies that develop in the period following the burn are suggested to be responsible for this condition [2, 3].

Neopterin is regarded as a non-specific biochemical marker of stimulated cellular immune response $[4,5]$. Neopterin levels are observed to increase in conditions such as viral infections, intracellular pathogens, autoimmune diseases, inflammatory diseases, allograft rejection, or malignant diseases [6]. It has been reported that the release of neopterin starts 3 days before the T-cell proliferation reaches its peak and the increase in neopterin levels may be observed one week before the specific antibody production [7]. Previous studies have shown that the burn trauma activates T-lymphocyte-macrophage interaction and leads to an increase in neopterin levels in the majority of burn patients compared to healthy individuals $[3,6]$.

Procalcitonin (PCT) is normally synthesized in the thyroid gland and during bacterial or fungal infections $[8,9]$. PCT has been shown to be a useful marker of sepsis in adult patient population in the intensive care units and emergency patients with infection $[10,11]$. In healthy individuals, the normal serum PCT values are below $0.05 \mathrm{ng} / \mathrm{mL}$. It has been reported to increase to $<0.5 \mathrm{ng} / \mathrm{mL}$ in case of local infections; to the values between $0.5-2 \mathrm{ng} / \mathrm{mL}$ in probable systemic infection, to $2-10 \mathrm{ng} / \mathrm{mL}$ in sepsis, and to the levels $>10 \mathrm{ng} / \mathrm{mL}$ in severe sepsis [12]. Recent studies demonstrated that it is possible to detect infection and septic complications in burn patients by monitoring the PCT plasma values [8].

White blood cell (WBC), C-reactive protein (CRP), sedimentation rate, or high fever are non-specific markers [13]. CRP is regarded as an infection marker, especially in acute bacterial infections [14]. Nevertheless, it is known to increase in various conditions including burns, trauma, surgery, tissue necrosis, immunemediated diseases, and cancer $[15,16]$.

In the light of these data, an early diagnosis and treatment of burn infections are of utmost importance to reduce mortality and morbidity rates. The aim of this study was to investigate the serum neopterin and PCT levels simultaneously with WBC and CRP levels in children aged 0-12 admitted to the burn unit of our hospital and to evaluate the relationship of these markers with burn wound infections (BWI). 


\section{Material and Methods}

\section{Study groups}

a) Patient Group (PG): As PG, 23 children (12 girls and 11 boys) who were following-up with burn wounds in Burn Unit of Bagcilar Training and Research Hospital between 0-12 years (mean age: $2.48 \pm 0.42$ ) were included in this methodologically designed study between March 2012-June 2013. The etiology of burns involved contact with hot fluids in 22 patients and flame burns in 1 patient. Percent burned total body surface area (TBSA) was calculated according to the Lund-Browder chart and patients with burns greater than $30 \%$ TBSA and those requiring intensive care were excluded from the study. The percentage of TBSA that was burned in patients varied between $3 \%-30 \%$ (mean TBSA (\%): $13.08 \% \pm 6.45 \%$ ) (Table I).

b) Healthy Control Group (HCG): As a HCG, 15 children (6 girls and 9 boys) between $0-12$ years (mean age: $3.20 \pm 2.42$ ) who were following-up with anatomical deformity and without any burn wounds were included in this study. Demographical data were recorded and PG and HCG were matched for age of the groups $(\mathrm{p}>0.05)$. All patients and their parents were informed about the study and they signed consent forms.

\section{Collection of serum samples}

Blood samples were collected on the first day of burn, on the seventh, on the fourteenth and on the $21^{\text {st }}$ day in the morning without any operation and ad-

Table I. Characteristics of PG and HCG

\begin{tabular}{lll}
\hline Characteristics & PG & HCG \\
\hline Number of subject & 23 & 15 \\
Gender (male/female) & $11 / 12$ & $9 / 6$ \\
Age (years) (Mean \pm sd) & $2.48 \pm 0.42$ & $3.20 \pm 2.42$ \\
Percent burned TBSA (Mean \pm sd) & $13.08 \% \pm 6.45 \%$ & 0 \\
Number of BWI & 11 & 0 \\
Number of septic patients & 1 & 0 \\
Mortality (\%) & 0 & 0 \\
\hline
\end{tabular}

PG: Patient Group, HCG: Healty Control Group, Mean \pm sd: Mean \pm standart deviation, TBSA: Total Body Surface Area, BWI: Burn Wound Infections 
ditional treatment (antibiotic treatment etc.) and serum fractions of blood samples were immediately separated and kept at $-80{ }^{\circ} \mathrm{C}$ until the study.

\section{Other clinical and laboratory procedure}

During the treatment and follow-up of the patients, complete blood count and biochemistry samples were also routinely collected and quantitative wound smear cultures, deep tissue cultures, blood and urine cultures were studied. Physical findings including fever, tachycardia and wound evaluation results were also recorded (Table II).

Besides systemic parameters such as fever, leukocytosis and acute phase reactants, local findings including scar formation, discolouring, edema, erythema, heat increase and sensitivity were also evaluated as burn wound infection criteria. Furthermore, in patients with pulmonary, urogenital, otolaryngological, ophthalmological etc. burns, possible causes of infection were ruled out. No prophylactic antibiotic treatment was applied who were admitted to our clinics with burn wounds. The antibiotic treatment was chosen in the light of physical examination, laboratory tests and culture results.

Table II. WBC, CRP, TBSA, fever, PCT and neopterin values of patient groups

\begin{tabular}{|c|c|c|c|}
\hline & $\begin{array}{l}\text { Infected patients }(\mathrm{n}=11) \\
\text { mean } \pm \text { sd } \\
\text { median (range) }\end{array}$ & $\begin{array}{l}\text { Non-infected patients }(\mathrm{n}=12) \\
\text { mean } \pm \text { sd } \\
\text { median (range) }\end{array}$ & $\begin{array}{l}\text { Statistical } \\
\text { value }\end{array}$ \\
\hline WBC $\left(\mathrm{mm}^{3}\right)$ & $\begin{array}{l}15144 \pm 3155 \\
16335(10863-18303)\end{array}$ & $\begin{array}{l}12446 \pm 3989 \\
11558(6238-18970)\end{array}$ & NS \\
\hline CRP (mg/L) & $\begin{array}{l}22.55 \pm 23.23 \\
10.88(4.21-80.79)\end{array}$ & $\begin{array}{l}14.88 \pm 17.42 \\
5.18(0.58-47.74)\end{array}$ & NS \\
\hline TBSA (\%) & $\begin{array}{l}14.36 \pm 6.516 \\
14(2-25)\end{array}$ & $\begin{array}{l}8.83 \pm 6.45 \\
7.5(3-25)\end{array}$ & $\mathrm{P}<0.039$ \\
\hline Fever $\left({ }^{\circ} \mathrm{C}\right)$ & $\begin{array}{l}38.2 \pm 0.844 \\
37.9(37.1-39.5)\end{array}$ & $\begin{array}{l}37.9 \pm 0.469 \\
37.7(37.1-38.5)\end{array}$ & NS \\
\hline PCT (ng/mL) & $\begin{array}{l}1.66 \pm 5.1 \\
0.07(0.03-16.92)\end{array}$ & $\begin{array}{l}0.24 \pm 0.24 \\
0.14(0.08-0.81)\end{array}$ & NS \\
\hline Neopterin (ng/mL) & $\begin{array}{l}7.3 \pm 9.2 \\
4.8(1.2-33.3)\end{array}$ & $\begin{array}{l}5.7 \pm 2.8 \\
4.9(3.3-12.3)\end{array}$ & NS \\
\hline
\end{tabular}

WBC, CRP, TBSA, fever, PCT and neopterin values of patient groups Mean \pm sd: Mean \pm standart devision, WBC: White blood cell, CRP: C-reactive protein, NS: not significant, TBSA: Total Body Surface Area, PCT: Procalcitonin 


\section{Laboratory tests}

Measurements of serum PCT and neopterin levels were applied simultaneously in a single run to the serum fractions of blood samples which were collected on the first, on the seventh, on the fourteenth and on the $21^{\text {st }}$ day and kept $-80{ }^{\circ} \mathrm{C}$. The PCT levels of the serum samples were measured using the monoclonal immunoluminometric method (B.R.A.H.M.S PCT Sensitive, BRAHM Diagnostic GmbH, Berlin, Germany). The method specific to the PCT molecule uses two separate monoclonal antibodies binding to the calcitonin and catacalcin regions. The minimum value detected by this method was $0.1 \mathrm{ng} / \mathrm{mL}$ and the measuring range was $0.1-500 \mathrm{ng} / \mathrm{mL}$, while the pathological limit was $>0.5$ ng/mL $[13,17]$. A commercial ELISA kit (Neopterin ELISA, DRG Instruments $\mathrm{GmbH}$, Berlin, Germany) was used according to the manufacturer's instructions to quantitatively determine the serum neopterin levels. Internal controls were used during the study. We performed the test in single run therefore we do not have inter-assay coefficient variation (CV). All calibrators and controls tested in two wells and our inter assay CV felled into 5.2-9.5\% (7.2) range which described in product manual. The pathological value was accepted as $\mathrm{ng} / \mathrm{mL}$.

\section{Statistical analysis}

Fischer's exact test was used in frequency and percentage comparisons between PG and HCG for biostatistical evaluation of this study results. To compare PG and HCG, we used Mann-Whitney U-test (data normally distributed). Quantitative variables were calculated with arithmetical mean \pm standart deviation and median. $\mathrm{p}<0.05$ was considered significant.

Ethics: This study was approved by the Non-Invasive Clinical Research Ethics Committee of Bagcilar Research and Training Hospital (Number: GOKAEK/2012-91, Date: 10 December 2012).

\section{Results}

Among the 23 patients enrolled in the study, 11 (47.8\%) were clinically and bacteriologically observed to have BWI. No BWI was detected clinically or bacteriologically in the other 12 patients. In the PG, patients were grouped as infected PG with BWI and non-infected PG without BWI (Table II). In quantitative smear cultures, the following infectious agents were detected: Staphylococ- 


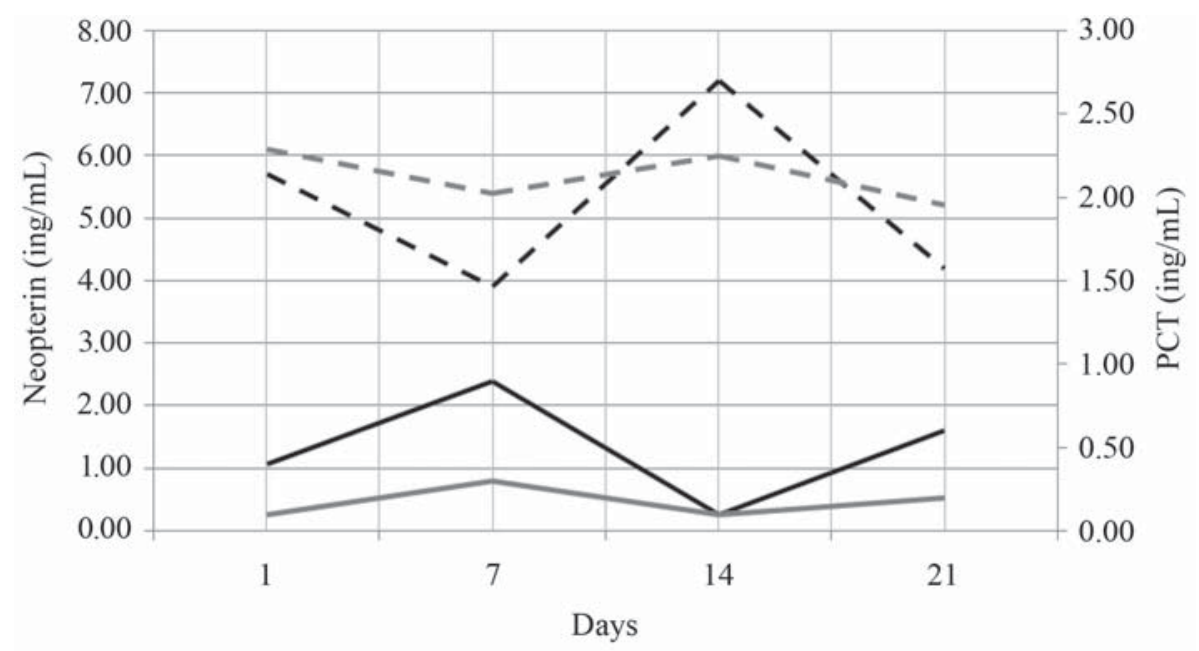

Figure 1. Mean values of neopterin and PCT in patients who developed burn wound infections and patients without burn wound infections

- Mean neopterin values of patients who developed burn wound infections
- Mean neopterin values of patients without burn wound infections
Mean PCT values of patients without burn wound infections

cus aureus in six patients, Pseudomonas aeruginosa in two patients, Staphylococcus epidermidis in one patient and Acinetobacter baumanni in one patient.

In one patient, methicillin-resistant $S$. aureus (MRSA) growth was accompanied by a positive cell culture and sepsis. Among the infected PG, the infection was detected between the fifth and the fifteenth day, with a mean value of 8.5 \pm 3.2 . A very high significant difference was detected between PG and HCG for PCT and neopterin positivity $(\mathrm{p}<0.0001, \mathrm{p}<0.0001$, respectively). Serum PCT levels of infected and non-infected PG were detected as $1.66 \pm 5.1 \mathrm{ng} / \mathrm{mL}$, $0.24 \pm 0.24 \mathrm{ng} / \mathrm{mL}$, respectively. Although, statistically significant difference between infected and non-infected PG for PCT levels was not detected, but PCT serum level was found higher in infected than in non-infected PG.

Neopterin levels were detected as $7.3 \pm 9.2 \mathrm{ng} / \mathrm{mL}$ and $5.7 \pm 2.8 \mathrm{ng} / \mathrm{mL}$ in infected and non-infected PG, respectively. Although, statistically significant difference between them for serum neopterin levels was not detected, but it was found higher in infected than in non-infected PG.

We also compared the classic infection indicators; WBC and CRP in this study. Although, no statistically significant difference was detected between infected and non-infected PG for WBC and CRP levels ( $>>0.05$ ), both of them were detected higher in infected PG than non-infected PG. 
Mean percent burned TBSA $14.36 \% \pm 6.51 \%$ and $8.83 \% \pm 6.45 \%$ in infected and non-infected PG, respectively. A statistically significant difference was detected between infection and percentage of TBSA that was burned $(p<0.039)$ (Table II).

Mean values of neopterin and PCT of patients who develope BWI and other patients only with burn wounds over 21 days period were shown in Figure 1.

\section{Discussion}

BWI and associated bacterial sepsis is the major cause of mortality and morbidity [18]. An early diagnosis of septic complications and the appropriate antibiotic treatment is of utmost important in order to increase the survival rates of burn patients [19]. In limited numbers of pediatric studies, Neely et al. [20] indicated that PCT had a sensitivity of $42 \%$ for early diagnosis of sepsis in 20 children with burns. Pourakbari et al. [21] concluded that rapid PCT test was superior to neopterin for anticipating bacterial infection in pediatric patients with bacterial infection. Mann et al. [8] indicated that PCT may be helpful to diagnose sepsis. Systemic bacterial infections cause marked PCT elevation. For example, E. coli endotoxin induces TNF- $\alpha$ and IL-6 followed by an increase of PCT [22]. Budkevich et al. [23] suggested the rise in their PCT levels may be related with bacterial complications. Barati et al. [13] studied with 60 burn patients with and without infection. They detected a significantly higher PCT level in the infected group as in our one patient with sepsis and elevated PCT level (5.19 ng/mL).

In this study, we detected a very highly significant difference between PG and HCG for PCT positivity $(\mathrm{p}<0.0001)$. Among patients with and without BWI, the mean PCT value was $1.66 \pm 5.1 \mathrm{ng} / \mathrm{mL}$ and $0.24 \pm 0.24 \mathrm{ng} / \mathrm{mL}$, respectively with no statistically significant difference. According to the Carsin et al. [24] serum PCT levels were increased during the first hours following burn and rapidly stabilised and they concluded that PCT was a useful marker for determination of the course of patients with burns following burn. But, other investigators suggested that PCT may be a useful marker for the diagnosis of severe infectious complications after burn [17, 20, 22, 25, 26]. Our results were in concordance with the results of Lavrentieva et al. [19] and Barati et al. [13]. PCT levels of our PG on day 1 were at local infection levels $(0.5 \mathrm{ng} / \mathrm{mL})$ due to the burn trauma. Considering the mean time point (on day 8) the infection was detected, PCT values of the infected PG were increased during the preinfectious period, showing a tendency to diminish later. The decrease of PCT levels in the subsequent days may be associated with the treatment response influencing PCT levels. We are of the opinion that PCT is an auxiliary marker of diagnosis. 
Neopterin levels were found to increase in burn injuries and a significant elevation in neopterin levels was not seen within 24 hours post-burn. The possible reason might be due to the late appearance of inducer interferon-gamma [7]. We detected a very high significant difference between PG and HCG for neopterin positivity $(\mathrm{p}<0.0001)$. Within the first 24 hours following the burn damage, the mean neopterin level was $5.8 \pm 3.2 \mathrm{ng} / \mathrm{mL}$ while neopterin level in HCG was $2.5 \pm 0.2 \mathrm{ng} / \mathrm{mL}$. These results suggested that the serum neopterin levels may have been increased in burn patients even in the absence of any infection. The mean neopterin value of the infected PG was $7.3 \pm 9.2 \mathrm{ng} / \mathrm{mL}$ in comparison to $5.7 \pm 2.8$ $\mathrm{ng} / \mathrm{mL}$ of non-infected PG. Also, considering day 8 , as the infection detection time, neopterin levels of the infected PG were found to decrease during the preinfectious period, only to increase in the postinfectious period. We also observed, neopterin levels were fluctuated as an increase after the burn trauma, and a decrease in the subsequent period, and another increase after the infection. In our only sepsis case, initially neopterin levels were increased to $5.8 \mathrm{ng} / \mathrm{mL}$ level and decreased to $3.5 \mathrm{ng} / \mathrm{mL}$ during the therapy. Yao et al. [3] detected increased neopterin levels in most patients on the day of 3 post-burn. Grabosch and Rokos [6] detected initially neopterin levels of 22 patients with burn injuries in the normal range. After first week, they were increased significantly thereafter. They suggested that elevated neopterin levels could not be attributed either to the burn itself or to the later events, the cellular immune system was shown to be highly activated. Our results were in concordance with the results of Yao et al. [3], Grabosch and Rokos [6]. Balogh et al. [2] detected a continuous increase in neopterin levels of 21 patients with burn until day 10, then a fluctuation for several weeks. They concluded that low neopterin levels in the presence of bacteraemia may have been caused by deleterious impairment of immune functions. Our results were in accordance with their results.

As a conclusion, although, no statistically significant difference was detected between PG who developed BWI and PG without BWI, it was detected that PCT and neopterin levels were increased in PG who developed BWI. The PCT levels were observed to increase during the pre-infectious period, while the neopterin levels were found to increase during the post-infectious period.

\section{Acknowledgements}

This study was supported by the Bagcilar Research and Training Hospital, Project number: 2012-91. We thank, Bagcilar Training and Research Hospital for the technical support and laboratory studies. 


\section{Conflict of Interest}

The authors declare that there is no conflict of interests regarding the publication of this paper.

\section{References}

1. Sheridan, R. L.: Sepsis in pediatric burn patients. Pediatr Crit Care Med 6, 112-119 (2005). Doi: 10.1097/01.PCC.0000161577.27849.BE

2. Balogh, D., Lammer, H., Kornberger, E., Stuffer, M., Schönitzer, D.: Neopterin plasma levels in burn patients. Burns 18, 185-188 (1992). Doi: 10.1016/0305-4179(92)90068-6

3. Yao, Y. M., Yu, Y., Wang, Y. P., Tian, H. M., Sheng Z. Y.: Elevated serum neopterin level: its relation to endotoxaemia and sepsis in patients with major burns. Eur J Clin Invest 26, 224-230 (1996). Doi: 10.1046/j.1365-2362.1996.128257.x

4. Fuchs, D., Weiss, G., Reibnegger, G., Wachter, H.: The role of neopterin as a monitor of cellular immune activation in transplantation, inflammatory, infectious and malignant diseases. Crit Rev Clin Lab 29, 307-341 (1992). Doi: 10.3109/10408369209114604

5. Huber, C., Batchelor, J. R., Fuchs, D., Hausen, A., Lang, A., Niederwieser, D., Reibnegger, G., Swetly, P., Troppmair, J., Wachter, H.: Immune response-associated production of neopterin. Release from macrophages primarily under control of interferon gamma. J Exp Med 160, 310-316 (1984). Doi: 10.1084/jem.160.1.310

6. Grabosch, A., Rokos, H.: Neopterin as parameter of cell-mediated immunity response in thermally injured patients. Burns 18, 113-116 (1992). Doi: 10.1016/0305-4179(92)90006-G

7. Elshahat, A., Elshahat, E. M. F.: Neopterin as a prognostic marker in burned patients. Egypt J Plast Reconstr Surg 30, 13-17 (2006). Full text available at http://www.medbc.

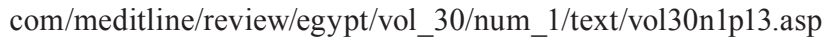

8. Mann, E. A., Wood, G. L., Wade, C. E.: Use of procalcitonin for the detection of sepsis in the critically ill burn patient: a systematic review of the literature. Burns 37, 549-558 (2011). Doi: 10.1016/j.burns.2010.04.013

9. Gilber, D. N.: Use of plasma procalcitonin levels as an adjunct to clinical microbiology. J Clin Microbiol 48, 2325-2329 (2010). Doi: 10.1128/JCM.00655-10

10. Ugarte, H., Silva, E., Mercan, D., De Mendonça, A., Vincent, J. L.: Procalcitonin used as a marker of infection in the intensive care unit. Crit Care Med 27, 498-504 (1999). Doi: 10.1097/00003246-199903000-00024

11. Hausfater, P., Garric, S., Ayed, S. B., Rosenheim, M., Bernard, M., Riou, B.: Usefulness of procalcitonin as a marker of systemic infection in emergency department patients: a prospective study. Clin Infect Dis 34, 895-901 (2002). Doi: 10.1086/339198

12. Harbarth, S., Holeckova, K., Froidevaux, C., Pittet, D., Ricou, B., Grau, G. E., Vadas, L., Pugin, L.: Diagnostic value of procalcitonin, interleukin-6, and interleukin-8 in critically ill patients admitted with suspected sepsis. Am J Respir Crit Care Med 164, 396-402 (2001). WOS: 000170651200012

13. Barati, M., Alinejad, F., Bahar, M. A., Tabrisi, M. S., Shamshiri, A. R., Bodouhi, N. O. L., Karimi, H.: Comparison of WBC, ESR, CRP and PCT serum levels in septic and nonseptic burn cases. Burns 34, 770-774 (2008). Doi: 10.1016/j.burns.2008.01.014 
14. Reinhart, K., Meisner, M., Brunkhorst, F. M.: Markers for sepsis diagnosis: What is useful? Crit Care Clin 22, 503-519 (2006). Doi: 10.1016/j.ccc.2006.03.003

15. Gabay, C., Kushner, I.: Acute-phase proteins and other systemic responses to inflammation. N Engl J Med 340, 448-454 (1999). Doi: 10.1056/NEJM199902113400607

16. Pileri, D., Accardo-Palumbo, A., D’Amelio, L., D’Arpa, N., Arnone, G., Grisaffi, C., Amico, M., Brancato, R., Lombardo, C., Conte, F.: Serum levels of cortisol, immunoglobulin and C-reactive protein in burn patients. Ann Burns Fire Disasters 22, 3-5 (2009). PMCID: PMC3188205

17. von Heimburg, D., Stieghorst, W., Khorram-Sefat, R., Pallua, N.: Procalcitonin - a sepsis parameter in severe burns. Burns 24, 745-750 (1998). Doi: 10.1016/S0305-4179(98)00109-0

18. Bargues, L., Chancerelle, Y., Catineau, J., Jault, P., Carsin, H.: Evaluation of serum procalcitonin concentration in the ICU following severe burn. Burns 33, 860-864 (2007). Doi: 10.1016/j.burns.2006.10.401

19. Lavrentieva, A., Papadopoulou, S., Kioumis, J., Kaimakamis, E., Bitzani, M.: PCT as a diagnostic and prognostic tool in burn patients. Whether time course has role in monitoring sepsis treatment. Burns 38, 356-363 (2012). Doi: 10.1016/j.burns.2011.08.021

20. Neely, A. N., Fowler, L. A., Kagan, R. J., Warden, G. D.: Procalcitonin in pediatric burn patients: an early indicator of sepsis? J Burn Care Rehabil 25, 76-80 (2004). Doi: 10.1097/01.BCR.0000105095.94766.89

21. Pourakbari, B., Mamishi, S., Zafari, J., Khairkhah, H., Ashtiani, M. H., Abedini, M., Afsharpaiman, S., Rad, S. S.: Evaluation of procalcitonin and neopterin level in serum of patients with acute bacterial infection. Braz J Infect Dis 14, 252-255 (2010). Doi: 10.1590/S1413-86702010000300009

22. Lavrentieva, A., Kontakiotis, T., Lazaridis, L., Tsotsolis, N., Koumis, J., Kyriazis, G., Bitzani, M.: Inflammatory markers in patients with severe burn injury. What is the best indicator of sepsis? Burns 33, 189-194 (2007). Doi: 10.1016/j.burns.2006.07.001

23. Budkevich, L. I., Lecmanov, A. U., Kolokolchikova, E. G., Soshkina, V. V.: Comparing the morphological changes in burn wound tissues and the procalcitonin concentrations. Int J Biomed 3, 23-26 (2013).

24. Carsin, H., Assicot, M., Feger, F., Roy, O., Pennacino, I., Le Bever, H., Ainaud, P., Bohuon, C.: Evaluation and significance of circulating procalcitonin levels compared with IL-6, TNF alpha and endotoxin levels early after thermal injury. Burns 23, 218-224 (1997). Doi: 10.1016/S0305-4179(96)00124-6

25. Sachse, C., Machens, H. G., Felmerer, G., Berger, A., Henkel, E.: Procalcitonin as a marker for the early diagnosis of severe infections after thermal injury. J Burn Care Rehabil 20, 354-360 (1999). Doi: 10.1097/00004630-199909000-00004

26. Lacour, A. G., Gervaix, A., Zamora, S. A., Vadas, L., Lombard, P. R., Dayer, J. M., Suter S.: Procalcitonin, IL-6, IL-8, IL-1 receptor antogonist and C-reactive protein as identificators of serious bacterial infections in children with fewer without localizing signs. Eur J Pediatr 160, 95-100 (2001). Doi: 10.1007/s004310000681 